\title{
GÉNESIS DEL CASTELLANO ANDINO DE ACOLLA
}

\author{
Yrma García Rojas* \\ Universidad Católica Sedes Sapientiae \\ ygarcia@ucss.edu.pe / yrmagarcia_ipnm@yahoo.es
}

Fecha de recepción: agosto de 2014 Fecha de aceptación: octubre de 2014

Resumen: El castellano llega al Perú con la conquista española (1532), en momentos en que el quechua es la lengua oficial del imperio incaico. En el virreinato, se instaura el castellano como medio de comunicación; sin embargo, la lengua peninsular no está exenta de cambios en su sistema lingüístico; esto, como consecuencia de un proceso natural del entrecruce de dos lenguas en contacto y propiciados además por factores históricos, geográficos y socioculturales. Estos hechos han jugado un rol importante en la formación de una variedad dialectal que ha logrado una nominación

* Yrma Doris García Rojas es Profesora graduada en la enseñanza del Inglés en el Instituto Pedagógico Nacional Monterrico y con estudios concluidos de Maestría en Lingüística de la Universidad Nacional Mayor de San Marcos. Tiene 15 años de experiencia en la docencia de la Educación Básica Regular, y otros 15 en la docencia a nivel de pre y posgrado. En la Universidad Católica Sedes Sapientiae desempeña el cargo de coordinadora de la carrera de Lengua Inglesa de la Facultad de Ciencias de la Educación y Humanidades, y con experiencia en las cátedras de Sintaxis, Análisis del Discurso y Adquisición de una Segunda Lengua. Ha asistido y participado en congresos nacionales e internacionales. El 2014 participó como ponente en la 48 Conferencia Anual de la Asociación Internacional de Profesores de Inglés como Lengua Extranjera en Inglaterra, Reino Unido. Es miembro internacional de IATEFL(International Association of Teachers of English as a Foreign Language) y TESOL (Teachers of English to Speakers of Other Languages). Los temas de su interés se relacionan con la Lingüística Andina. 
especial y específica como español o castellano andino. En este trabajo, el principal interés es realizar una reseña de los aspectos históricos, geográficos y sociales más relevantes respecto a la lengua quechua para luego abordar el castellano andino del Perú dentro del marco referido. Finalmente, aplicando el mismo enfoque, se revisará una de las variedades de castellano andino peruano que se desarrolla en un distrito de la provincia de Jauja en la región Junín, por lo que hemos convenido asignarle el nombre del lugar: castellano andino de Acolla.

Palabras Clave: Quechua, castellano andino, castellano andino de Acolla

\section{GENESIS OF ACOLLA'S ANDEAN SPANISH}

ABstract: When the Spanish conqueror arrived in Peru (1532), the Incas had Quechua as their official language. In the viceroyalty times, the Spanish language was imposed as the medium of communication; nevertheless, the peninsular language was not prevented from suffering linguistic changes in its system, due to the natural process every language undergoes when it is in contact with another, a fact, which in turn, was furthermore fostered by historical, geographical and sociocultural factors. All these have played an important role in the emergence of a dialectal variety known as Andean Spanish. In this paper, the main aim is to develop a review of the most relevant historical, geographical and sociological aspects with respect to Quechua. Afterwards, within the same theoretical framework, we will focus on the Peruvian Andean Spanish. Finally, following the same approach, we will provide some information on an Andean variety developed in a district located in the province of Jauja (Junin), which, for this study, will be designated by the name of the place: Acolla's Andean Spanish.

Keywords: Quechua, Andean Spanish, Acolla's Andean Spanish 


\section{INTRODUCCIÓN}

$\mathrm{E}$

s sabido por muchos que el Perú es uno de los pocos países que se distingue por ser pluricultural, multiétnico y multilingüe. Esta caracterización no se debe a hechos recientes, por el contrario, data de periodos anteriores al incanato. En su momento, los incas conquistaron para sí las antiguas poblaciones cuyas culturas y lenguas diferían unas de otras. Con el afán de unificarlas como un estado y que esto permitiera su fácil administración vieron oportuno establecer una política lingüística. Para ello, se implantó el quechua como idioma oficial, sin que esto significara restricción alguna para que las poblaciones sometidas utilizaran sus lenguas aborígenes.

Con la conquista española, la lengua oficial inca sufre un impacto inesperado y se produce el contacto de lenguas, en este caso, castellano y quechua. Actualmente, las investigaciones lingüísticas resaltan la expansión del castellano en el Perú, especialmente en las zonas en las que otrora tanto el quechua como las distintas lenguas indígenas eran de uso en la comunicación de sus habitantes. Sin embargo, es preciso remarcar que el crecimiento del castellano en el Perú no ha sido homogéneo ni tampoco unificador; pues, se advierte en el idioma matices diversos que se enmarcan dentro de una clasificación que generan nominaciones como castellano andino y castellano no-andino con variadas características lingüísticas (Escobar 1990: 17). ${ }^{1}$

El contacto de lenguas a nivel social ha dado origen a diferentes variedades monolingües de castellano. En el caso del Perú, se

1 Lingüista peruana dedicada al estudio del castellano andino hablado por inmigrantes bilingües establecidos en Lima. Registra sus hallazgos en su libro Los bilingües y el castellano en el Perú (1990). 
distingue entre el castellano andino y el castellano no-andino (Escobar 1978:39). Estas dos variedades presentan diferentes características lingüísticas en los diferentes niveles de la gramática de una lengua. (Escobar 1978:e.g. 48-51)

El castellano andino, a su turno, ha seguido diversas rutas en el trayecto de su expansión. Esto ha producido dialectos que si bien comparten rasgos que los identifica como castellano andino, el cruce «ha dado como resultado variedades del castellano que presentan características propias de las lenguas de contacto, como generalizaciones o transferencias de la lengua materna, que constituyen la fisonomía propia de las variedades de castellano en el Perú» (Pérez Silva 2006: 13).

Rodolfo Cerrón-Palomino ofrece un acucioso estudio del castellano de la zona rural del Valle del Mantaro en su libro Castellano Andino (2003). En él se plasma una descripción lingüística del castellano de la sierra central del Perú como resultado del contacto de lenguas, en este caso el castellano y el quechua. Cerrón-Palomino agrega que la variedad que resulta de este cruce dista del estándar porque posee una estructura interna y organización propia bajo la actuación de diversos factores que se enmarcan no solo en lo lingüístico, sino también en lo económico, social, sicológico, político y literario. Sobre estas variedades dialectales, vistas desde un enfoque no solo horizontal — geográfico o territorial (diatópico) — que permite hablar de variedades regionales, sino a la vez vertical o sociocultural (diastrático), Cerrón-Palomino invoca que:

[...] debe rechazarse el mito de la «superioridad» $\mathbf{o}$ «inferioridad» de las variedades lingüísticas, hay que ver en estos no una 
«desviación» de la forma estándar, sino formas que poseen su propio sistema, es decir, su propia organización interna. Pues bien, esto que acabamos de decir es absolutamente exacto desde un punto de vista puramente lingüístico. (2003: 23)

Habiéndose forjado el castellano andino un sitio en la clasificación del castellano en América, Merma corrobora el fenómeno no solo como el habla de bilingües. Además, lo verifica en monolingües:

Su estudio resulta sumamente complejo, puesto que no solo es empleado por bilingües que adquieren el español como segunda lengua, sino también por hablantes monolingües del castellano que no conocen el quechua y que viven en la sierra peruana, especialmente en áreas rurales o urbano marginales, e incluso en zonas urbanomarginales de las grandes ciudades de la costa, donde los hablantes bilingües se han asentado de modo estable como consecuencia de los procesos migratorios que se vienen incrementando en las últimas décadas. (Merma 2004: 193-194)

El castellano andino de Acolla, tema principal de este trabajo, es una variedad dialectal resultado del extenso proceso de entrecruce del castellano estándar del Perú y el quechua hablado en la provincia de Jauja, clasificado como shausha-huanca. El objetivo del presente trabajo es elaborar una reseña panorámica y brindar una visión general del proceso de formación del castellano en cuestión, resaltando factores de carácter histórico, geográfico y social que forjaron el surgimiento de una nueva variedad dialectal de 
castellano andino en la provincia de Jauja, región Junín. En este trabajo, el quechua, el castellano andino del Perú y el castellano andino de Acolla serán abordados dentro del mismo marco teórico y siguiendo una metodología descriptiva-informativa.

\section{EL QUECHUA: FILIACIÓN. DATOS HISTÓRICO-GEOGRÁFICOS}

«Esta zona de América, antes de la llegada de los españoles, estuvo caracterizada por la pluriculturalidad y el plurilingüismo. En ese extenso período anterior a la conformación del Tawantinsuyo, se desarrollaron innumerables sociedades con diversos sistemas políticos, económicos, religiosos y sociales». (Robledo Ríos 2006: 63). La situación sociolingüística de las antiguas culturas igualmente presentaba un panorama variado. En la zona de la costa norte del Perú, por ejemplo, se hablaban idiomas que hoy yacen extintas como la lengua Tallana, Sechura, Olmos, Mochica y Quingnam. En el sureste de la sierra, la lengua que mayor expansión había logrado era el aymara, ${ }^{2}$ desde la sierra central del Perú llegando hasta Bolivia y Chile por el sur.

Entre los otros grupos lingüísticos importantes que existían, se pueden mencionar las lenguas que se hablaban en la costa y sierra norteñas del actual Perú, como el quignam, el mochica, el culle o el tallán, todas ellas desaparecidas en diferentes etapas de la historia del territorio andino; las lenguas que se hablaban en la sierra sur como el puquina, el callahualla o el uru-chipaya (solo sobrevive esta última, cuyos hablantes viven en las orillas del

2 El aymara junto con el jaqaru y kauki forman parte de una familia lingüística denominada Jaki. El jaqaru se habla aún en el pueblo de Tupe y Kauki en el de Cachuy; ambos situados en Yauyos, en la sierra sureste de Lima. 
lago Poopo, en Bolivia); y el aimara, que se hablaba en regiones bastante más extensas en comparación con aquellas donde se le encuentra hoy, como la sierra de Lima, Ica, Ayacucho, Apurímac, Arequipa, Cuzco y el altiplano peruano-boliviano, donde ha hallado su refugio actual. (Estrada y Naters 2006: 166)

La diversidad lingüística en la etapa preinca era mucho más compleja de lo que podía parecer. El motivo es que en cada valle de la costa se hablaba una lengua distinta y en un mismo valle se hablaban dos o más lenguas. Sin embargo, de todas, fue el quechua que cumplió un rol unificador en el imperio incaico. Aunque el término quechua se entienda como si fuera una sola lengua, los estudiosos de esta lengua manifiestan que el quechua es la nominación que alberga a toda una familia lingüística con distintas variantes dependiendo de las zonas geográficas en las que se originaron. Hardman señala que «La otra gran familia de la sierra peruana, es la familia Quechua. No es una sola lengua, hay por lo menos seis lenguas, y estas lenguas Quechua, tienen variación dentro de sí, así que algunas tienen también dialectos» (2004: 12, las negritas corresponden al original).

Sobre la expansión del quechua, existen dos corrientes antagónicas, aunque últimamente se vienen ensayando otras nuevas. Nos referiremos a las primeras, ya que están basadas en estudios extensos, serios, sistemáticos y científicos. La primera corriente sostiene que el quechua nace en el Cuzco y que su difusión a las distintas zonas se llevó a cabo como parte del proceso de conquista de los pueblos. La segunda, representada por Torero y CerrónPalomino, postula la tesis que el quechua posee sus cimientos en una zona de la sierra de Ancash. Los pobladores comerciantes de este lugar impulsan la emigración hacia el sur y luego a la costa a inicios del siglo I de nuestra era y se convierten en los responsables de la difusión del quechua. Más 
adelante, la emigración se desplazaba hacia el norte de Ancash y luego hacia al sur llegando al Cuzco. Para el siglo XIV, el quechua ya había sido adoptado como lengua oficial de los incas y su expansión continuó hacia el norte llegando a Ecuador y por el sur, a Bolivia. Estrada y Naters ratifican esta postura al sostener que «al llegar los incas a la región andina, hallaron un panorama multilingüístico en el que convivía una gran variedad de lenguas, además de encontrar al quechua expandido a lo largo de la mayor parte del área andina» (2006:166).

Es de resaltar, que en el incanato, existía una política de tolerancia hacia la diversidad lingüística y cultural de sus pueblos. Se permitió que estos preserven y utilicen sus lenguas nativas mientras que el quechua era utilizado como idioma oficial de los incas y la nobleza. La adopción del quechua era una estrategia frente al reto que el Imperio Incaico enfrentaba en sus inicios de desarrollo: lograr la unificación administrativa de pueblos con distintas culturas y lenguas. Sin embargo, esta política de total control sobre los pueblos sometidos provocó más adelante una crisis en el sistema del gobierno incaico generándose la división y luego la guerra civil que terminaron por destruirlo. Esto hace que el sistema se debilite y en consecuencia la lengua quechua pierda su hegemonía ya que los pueblos empiezan a diversificarse y a retomar sus lenguas originales. «El proceso de quechuización propiciado por los incas se vio interrumpido y quedó suspendido. El proceso de conquista española se había iniciado. De este modo, se daría paso a la difusión del castellano en tierras americanas, oportunidad que la Corona española no desaprovechó» (Robledo Ríos 2006: 64).

Estrada y Naters sostienen que la variedad de quechua que se difundió en el incanato fue el quechua chinchay. Así, 
Lo cierto es que, cuando los españoles llegaron al territorio andino, el quechua chínchay estaba muy difundido, aunque no era ni la única lengua ni el único dialecto quechua, como se ha podido observar. En la primera mitad del siglo XVI, existían muchas regiones bilingües (donde se hablaba quechua chínchay $y$, junto con este, otras lenguas) y bidialectales, es decir, en las que se hablaba quechua chínchay y algún otro dialecto de este idioma. (2006: 169)

La clasificación dialectológica del quechua ha sido una tarea muy ardua y compleja para los lingüistas debido al entrecruzamiento de isoglosas como lo menciona Rataj (2005) y por la interpenetración de las variedades quechuas en el pasado. Adelaar refiere que desde el punto de vista genético y clasificatorio, el quechua debe dividirse en dos ramas principales. En los años 60, Gary Parker y Alfredo Torero se dedicaron a realizar la división dialectológica del quechua cada uno por su lado y Rodolfo Cerrón-Palomino realiza una revisión de estas clasificaciones. Parker y Torero clasifican los dialectos quechuas como Quechua A o Quechua II y Quechua B o Quechua I respectivamente.

«Parker recoge los resultados del estudio de Rowe y afirma que el quechua A se habla en los departamentos del Cuzco, Puno, parte de Arequipa y Apurímac (al este de Abancay)»(Carvajal, 2004: s/n). La denominada Quechua B por Parker (1963), y Quechua I por Torero (1964) o también Quechua Central (Mannhein, 1985a, Landerman 1994) ocupa un área compacta y continua en la sierra central, incluyendo las zonas Andinas de los departamentos de Ancash (a excepción de la provincia de Pallasca en el norte de Ancash), Huánuco, Pasco y Junín, algunas zonas andinas de Lima 
y algunos distritos de los departamentos de Huancavelica, Ica y La Libertad (Adelaar 2004: 185). En la sección anexo, el mapa 01 de Heggarty, quien a su vez toma la clasificación de Cerrón-Palomino, serán de gran ayuda para mayores detalles.

Siguiendo a Adelaar, el Quechua B o Quechua I constituye un complejo fragmentado de dialectos con un número de rasgos comunes claros. Agrega que Torero (1974) propone una división aún más refinada de 5 subgrupos. El cuarto (letra d. en la clasificación que hace Torero) corresponde a la variedad Jauja-Huanca que incluye los vestigios del área de Junín de habla Quechua y el distrito de Cacra en la provincia de Yauyos (Lima).

Quechua B or I constitutes a heavily fragmented dialect complex with a number of clear common features. A more refined subdivision into five subgroups is proposed in Torero (1974). ... d. Jauja-Huanca includes the remainder of the Quechuaspeaking area of Junin; and the district of Cacra in the province of Yauyos (Lima). (2004: 185)

El origen del nombre quechua proviene de una serie de designaciones de tipo etnológico y geográfico y, en algunos casos, estigmatizados por los propios prejuicios de la cultura occidental, y en otros, aprovechando las nominaciones insultantes provenientes de grupos étnicos rivales tal como revela Cerrón-Palomino. Más parece ser que la lengua no poseía un nombre específico y se hacía referencia de ella como «lengua general», inclusive el cronista Garcilaso de la Vega así la designaba. Lo insólito es que la misma 
designación le correspondía al aimara, al puquina, y se dice que al mochica también. Con el propósito de diferenciarla de estas lenguas, se decía la lengua «más general» o también «lengua del inca» o «lengua del Cuzco». El dominico Fray Domingo de Santo Tomás (1560) fue el primero en imprimir el nombre quichua o Chinchay para referirse a la lengua y sus variantes y se encarga de redactar la primera gramática del quechua. Resulta curioso saber que se ensayaron otras denominaciones como qqichua, kichua, kichwa, por mencionar algunos. Estas diferentes escrituras se basan en el habla.

Los lexicográficos refieren que el término quechua etimológicamente significa 'región' o 'zona templada'. Pedro Cieza de León utiliza el término como nombre de un pueblo o "una nación antigua" a manera de etnónimo y el nombre se extiende a la lengua que el grupo habla. Otros prefieren el término 'runa simi' cuyo significado es "lengua del hombre" o "lenguaje humano" que según Torero se utilizó a partir de la colonia y nunca antiguamente como algunos refieren. Por su parte, Adelaar ofrece un breve recuento de lo que pasó demográficamente y lingüísticamente con el quechua en la colonia.

After the Spanish power had become consolidated, the former Inca domain was ruled by a viceroy, who kept his residence in Lima. The Indian population suffered a demographic decline of dramatic proportions, which continued throughout most of the colonial period. Three of the principal Andean languages, Qechua, Aymara and Puquina, acquired the status of 'general languages' (lenguas generales) to be used in the administration and for religious purposes. Quechua, already an official language during the final period of Inca administration, was by far the 
most important one, followed by Aymara [...]. Notwithstanding a short revival of the Quechua language during the early times of independence at the beginning of the nineteenth century, the prestige of the Andean languages declined dramatically, and they gradually became confined to rural areas. (2004: 167)

Asimismo, asegura que fueron tres las lenguas que adquirieron el estatus de lenguas generales a la llegada de los españoles al Tawantinsuyo: (a) el quechua, (b) el aymara y (c) el puquina. Aguirre Villanueva, en cambio, manifiesta que «las lenguas generales eran cuatro: el quechua, el aimara, el mochica y el puquina» (2006: 85). Hasta el siglo xx, las zonas altas de la sierra del centro del Perú tuvieron como dominio indiscutible al Quechua, incluyendo las zonas andinas del departamento de Ancash, Huánuco, Pasco y Junín (Adelaar 2004: 173). «Until the twentieth century, the highlands of central Peru have been the undisputed domain of Quechua. It includes the Andean parts of the departments of Ancah, Huánuco, Pasco and Junín» (Adelaar 2004: 173). Al respecto ver el Apéndice B.

El quechua continuó siendo el idioma principal de los habitantes andinos hasta el siglo pasado. Es preciso mencionar que el 27 de mayo de 1975, el Presidente del Perú de entonces, Juan Velasco Alvarado, lo declaró lengua oficial y le confirió los mismos derechos que protegían al castellano. «Por este motivo, dio una disposición para que los canales de televisión transmitieran segmentos en quechua, lengua nacional» (Tavera Peña 2006: 44). En el Capítulo I, artículo 48. ${ }^{\circ}$ de la Constitución Política del Perú de 1993, se lee lo que sigue: «Son idiomas oficiales el castellano y, en las zonas donde predominen, también lo son el quechua, el aimara y las demás lenguas aborígenes, según la ley» (15). Pese a estas declaraciones constitucionales, 
en las últimas décadas, se viene hablando de la decadencia de las lenguas indígenas, el quechua incluido. Esto se debe a múltiples factores: político, social, económico y lingüístico. De otro lado, las investigaciones realizadas por lingüistas señalan la intervención de una diversidad de variables sociales en el uso del quechua.

El uso de las lenguas está en función principalmente con las variables de edad, sexo y escolaridad: se preserva el uso del quechua más en contextos familiares antes que en la calle, entre las generaciones adultas y principalmente las ancianas más que entre los niños y jóvenes. Asimismo se ha registrado el mayor uso entre la gente menos instruida, que entre los más escolarizados; y también entre las mujeres antes que entre los varones. (Julca Guerrero 2002: 60)

El factor social, también juega un rol preponderante en la expansión o extinción de una lengua. En el caso del quechua, contribuye a un deterioro considerable de su uso frente a un impulso insistente del castellano, el mismo que se ha visto favorecido por otros factores que juegan a su vez en contra del quechua. Solo que el castellano que se viene difundiendo con dinamismo imparable no corresponde a la variedad estándar, o como otros la catalogan, la variedad culta del español, y, más bien es el castellano que emerge del contacto con las distintas variedades de quechua. Originado principalmente en la sierra, esta variedad de castellano logra su nombre por el espacio en el que se desarrolla tal como veremos en el siguiente apartado. 


\section{EL CASTELLANO ANDINO: FILIACIÓN. DATOS HISTÓRICO- GEOGRÁFICOS}

Los romanos, motivados por su afán expansionista, llevan el latín a la península ibérica por los años 200 a. C. El latín, descendiente de una vertiente de lenguas romances — a su vez provenientes de la familia de lenguas indoeuropeas-, logra su expansión convertido en diversos dialectos que luego alcanzaron el estatus de idiomas como el portugués, francés, italiano, rumano y castellano o español. Menéndez Pidal, en relación al español, aduce que "la base del idioma es el latín vulgar, propagado en España desde fines del siglo III a. C., que se impuso a las lenguas ibéricas». Los sucesos descritos por Menéndez se repiten en la historia que envuelve la expansión del español en territorio americano. Los españoles conquistan América, fundan sus colonias a lo largo y ancho del continente americano e imponen su idioma sobre las lenguas de cada territorio sometido.

Hoy en día se habla del mundo hispanoparlante para referirse a la nación peninsular y las naciones de América que tienen el español como lengua oficial. Esta idea puede inducir a pensar que el español goza de unidad y homogeneidad lingüística en la comunidad iberoamericana. Pues, esto no es así, el mismo Cerrón-Palomino distingue entre español general, español americano y español peruano no solo para designar las variantes de manera territorial sino para resaltar las diferencias lingüísticas entre ellas ya que, en algunos casos, son muy marcadas. Se puede inferir entonces que el español americano es un conjunto de dialectos cuya nominación corresponde al país de procedencia para fácil identificación pero como dice García Moutón (2007), «que, antes de hablar del español de América, hay que conocerlo. No es una simple extensión del español de España, sino una lengua con características propias que hay que describir, clasificar y respetar». 
El español, al instalarse en los pueblos y territorios del continente americano, inevitablemente entra en contacto con las lenguas aborígenes y como consecuencia de este contacto se originan variedades lingüísticas con peculiaridades en su fonética, morfología, sintaxis y gramática. El español de México, por ejemplo, tiene rasgos propios que lo distingue de aquel de los países más próximos por el lado de América Central, como Honduras, Nicaragua, Costa Rica. El español de Colombia, Venezuela y Ecuador tienen lo suyo comparado con el español de Perú por el lado norte. Bolivia, Argentina y Chile tienen su propio castellano que puede ser fácilmente reconocido del nuestro por el lado sur.

La intercomunicación entre integrantes de la comunidad de habla española es posible, se dice, para un grupo reducido de hispanoparlantes letrados o instruidos. Y si a esto se agrega que la intercomunicabilidad es más estable en el plano escrito que en el oral con mayor razón estaríamos frente a una heterogeneidad que es propia de toda lengua viva en pleno dinamismo.

... porque una de las características inherentes a toda lengua es su heterogeneidad. Una lengua no es, pues, como se cree, un sistema completamente homogéneo; por el contrario, es lo que podríamos llamar, empleando la ya clásica terminología de Weinreich (1968: 307), un diasistema, es decir, un sistema de sistemas (diferenciados). (Cerrón-Palomino 2003: 24-25)

En el español de América, podemos advertir una relativa intercomunicación entre sus usuarios pero esto no alcanza a todos sino a un grupo minoritario; la lengua escrita como sabemos no refleja las peculiaridades de las variables del español hablado en cada país del continente, porque, 
como asevera Cerrón-Palomino, es más rígida y conservadora. Robledo Ríos además, nos insta a ser conscientes de que,

La situación social y lingüística de las poblaciones americanas, como en la mayoría de sociedades, ha sido producto de un complejo proceso histórico, político y social. En nuestro caso, existe un factor imprescindible, que constituye el punto de partida para la interpretación y comprensión de dicho proceso $y$, por tanto, de nuestra realidad actual: el contacto cultural con el mundo europeo. Esta situación constituye un factor que debe considerarse para el análisis acerca del contexto lingüístico y social contemporáneo. (2006: 61)

Arboleda Toro (2000: 85) se adentra más allá de las variedades americanas del español y remarca la existencia del español andino americano al decir que «existe una variedad de español conocida en el mundo académico como español andino, que, junto a la zona serrana del noroeste argentino, Bolivia, Perú y Ecuador, se habla en el extremo suroccidental de Colombia». Arboleda agrega además, que en el afán de estudiar el castellano americano y sus dialectos, Pedro Henríquez Ureña (1921) propone una división en cinco zonas dialectales y es la tercera que estaba constituida por la «región Andina de Venezuela, el interior y la costa occidental de Colombia, el Ecuador, el Perú, la mayor parte de Bolivia y tal vez el Norte de Chile». Aunque se han detectado imprecisiones en los datos por ser un estudio muy arriesgado y provisional, Henríquez Ureña acota que el carácter de cada zona dividida «se debe a la proximidad geográfica de las regiones que las componen, los lazos políticos y culturales que las unieron durante la dominación española 
y el contacto con una lengua indígena principal. (Henríquez Ureña, 1978: 10)» (Arboleda Toro: 86).

Ya vimos cómo el Imperio Incaico se extendió desde el sur de Colombia hasta el noroeste de Argentina y que para sus habitantes. El quechua fue la lengua de comunicación y como esta misma expansión geográfica corresponde al virreinato, el quechua y el español tuvieron que convivir desde la época en que se inició la colonia hasta nuestros días. En la actualidad, este hecho histórico puede ser corroborado por estudios lingüísticos en los distintos países en los que el español andino se configura como una variedad que convive con el español estándar.

Según Anna María Escobar, Muysken (1981), por ejemplo, realizó un estudio sobre los hablantes bilingües quechua-castellano en el Ecuador. Arboleda (86) en su artículo El español Andino destaca que en el sur de Colombia podemos encontrar zonas donde el español andino es una lengua que aún no ha sido objeto de estudio. Por otro lado, confirmando lo que ya Arboleda había comentado, el español andino también lo encontramos en Argentina. En el XII Congreso del ALFAL (Asociación de Lingüística y Filología de América Latina), realizado en Santiago de Chile en agosto de 1999, Juana del Valle Rodas y Ana María Fernández Lávaque desarrollan la ponencia sobre su obra "Presencia del Quechua en el español del noroeste argentino" y "Presentan datos históricos y algunos rasgos fonéticos, morfosintácticos y léxicos para sustentar que el español hablado en el noroeste argentino es una variedad del español andino" (2000: 91).

Arboleda, haciendo referencia al estudio del castellano andino, resalta que las obras «dedican rasgos específicos del español andino y se apoyan en datos, del habla peruana, la mejor estudiada, de la boliviana y la del noroeste argentino; en muy pocas ocasiones, de la ecuatoriana, y menos 
aún, de la colombiana» (2000: 92). Hay dos puntos que resaltar respecto al tema: (a) el estudio del castellano andino correspondiente al Perú ha sido más fructífero que en otros países de Sudamérica y (b) se corrobora además su gran expansión por el lado del continente que nos corresponde, es decir al Perú (Ver Apéndice 3).

\subsection{El castellano andino del Perú: Filiación. Datos histórico- geográficos}

Los españoles llegaron al imperio incaico del Tawantinsuyo que se encontraba en medio de una grave crisis interna y externa en 1532 y redujeron a su autoridad máxima, en ese entonces el inca Atahualpa, el 16 de noviembre del mismo año. Este evento, se dice, es el inicio de manera oficial de la conquista española. Existen muchas versiones sobre el hecho que desencadenó el apresamiento de Atahualpa. Todos versan sobre la Biblia que le fue entregada al inca jefe como señal de sometimiento a la Corona de manera pacífica. Sin embargo, cronistas de la época relatan que hubo agravios de una y otra parte, y obviamente las narraciones están sujetas al punto de vista que cada escritor asume. Lo que sí es seguro es que...

De esta forma se registró para la historia la excusa que justificó el dominio. Con dicho enfrentamiento, se inició una relación basada en una interpretación subjetiva y etnocéntrica de la realidad. En este contexto, la escritura estableció la separación de la población entre sujetos activos, los de mentalidad occidental, y sujetos pasivos, nativos americanos convertidos en objeto de observación: los «individuos» y los «otros», respectivamente. (Robledo Ríos 2006: 69) 
A la llegada de los españoles, los cruces de culturas y de lenguas eran inevitables: castellano y quechua. Dicen los lingüistas que inicialmente la idea de los peninsulares era lograr el sometimiento total de los indios imponiéndoles la lengua española a través de la evangelización. Esta estrategia no resultó ser la más acertada ante la diversidad de lenguas indígenas. Entonces la corona decidió que la evangelización se hiciera en quechua pese a que esto podría significar un peligro para el fortalecimiento de la administración colonial. El uso del quechua en el proceso de evangelización, produjo la necesidad de su estudio e investigación así como la producción literaria. Este hecho fue ventajoso para el resurgimiento del quechua pero no por mucho tiempo.

El desarrollo de la lengua fue bloqueado, después, mediante una serie de reformas que se dieron aproximadamente a partir de mediados del siglo XVIII en el gobierno de Carlos III. Entre otras medidas, la Corona ordenó la expulsión de los jesuitas en 1767 y dispuso continuar la evangelización en español en 1772, lo que significó un duro golpe para la mínima difusión que se había logrado de las lenguas aborígenes, a favor, principalmente, de las elites indígenas. (Robledo Ríos, 2006: 73)

Las medidas en favor del uso del castellano y en contra del quechua se dice también que obedecían al peligro que representaba para la Corona los alzamientos revolucionarios de Túpac Amaru. Pues, se descubrió que este estaba liderando el movimiento independentista y animaba a los indios para que se sumen a esta causa. Pese a todos los esfuerzos de la corona 
española por erradicar el quechua del virreinato del Perú en un principio, los habitantes de las zonas andinas se resistían a aprender el idioma español e insistían en utilizar el idioma nativo, el quechua.

Se pudo observar en la investigación bibliográfica para el desarrollo de este trabajo que algunos lingüistas utilizan el término español andino y otros el de castellano andino. Diríamos que la preferencia por uno u otro término es personal y que no afecta en nada la descripción y caracterización de la variedad del castellano en cuestión. Merma Molina, en su tesis doctoral, utiliza la palabra español y en una nota a pie de página aclara la elección de un término sobre el otro:

En Hispanoamérica se ha preferido dominar a esta lengua propia de la región andina como castellano andino. Sin un afán de desacuerdo, en este trabajo emplearemos la denominación de español andino, siguiendo las consideraciones de la Real Academia de la Lengua Española que deja clara su preferencia por el término español, y que reserva la palabra castellano para el dialecto del antiguo Reyno de Castilla, si bien se admite su uso en España para distinguirlo de otras lenguas oficiales. (2007: 4)

Cerrón-Palomino, en cambio, se inclina por la nominación castellano andino y esta es la que prevalecerá para este estudio y se respetará la preferencia de cada autor al momento de citarlos. Lo seguro es que ambos términos son referentes del mismo sistema lingüístico. Por lo tanto, su procedencia histórica es la misma. 
El fenómeno de la heterogeneidad lingüística es más contundente en el caso del español peruano. El español hablado en la capital coincide con el estándar y es el modelo que se aspira dominar frente a otras variedades, que por oposición, son consideradas como de la variedad del español noestándar. En 1990, Ana María Escobar ya había ensayado una clasificación que se enmarcaba entre castellano andino y castellano no-andino, basada «en un aspecto importante de la dialectología hispánica, i.e. el uso o no del contraste entre $/ \lambda / \mathrm{y} / \mathrm{y} / »(17)$.

El castellano andino, como el mismo nombre refiere, es el castellano que se habla en toda la región andina y costa sur. La variedad no-andina, se refiere al castellano de la zona amazónica, costa norte y centro del Perú. Agrega la lingüista, que el castellano no-andino es el que se aproxima más al estándar y que este es el que predomina en Lima, la capital. «De lo dicho anteriormente se desprende que el español hablado en el país, no es, pues, un sistema monolítico; por el contario, es también un diasistema formado por subsistemas diferenciados» (Cerrón-Palomino 2003: 26). El español o castellano andino es el producto de la influencia que ejercieron sobre el español otras lenguas vernáculas como el quechua y el aimara específicamente.

En 1992, Caravedo identifica tres variedades de español en el Perú que coinciden con la división geográfica de nuestro territorio: (a) el español costeño, (b) el español andino y (c) el español amazónico. De la descripción acuciosa que elabora con respecto a la variedad costeña en los diferentes niveles (fonológico, morfológico, sintáctico), hace notar que es muy usual la formación de diminutivos y aumentativos no solo de adverbios (ahoritita, tempranazo, tardazo), sino de gerundios como el de vente corriendito. 
Las diferentes variedades de quechua dispersas en los pueblos o regiones de los andes han contribuido a una clasificación del castellano andino peruano que se pueden diferenciar a partir del contacto con la variedad de quechua que se habla en el lugar. Este hecho hace posible hablar de castellano andino de Huánuco, castellano andino de Ancash, castellano andino de Ayacucho, castellano andino de Cuzco, castellano andino de Arequipa por mencionar solo algunos y que creemos podrían devenir en nombres más específicos dependiendo de la variedad subdialenctal de quechua hablado en la zona.

Rataj (2005) al igual que Zavala (1996) y otros lingüistas insisten en que hay que estudiar el castellano andino en un contexto de bilingüismo. Asimismo, sostienen que la influencia de las lenguas andinas no solo se percibe en el español del bilingüe sino también en el del monolingüe. «[...] Los hablantes monolingües del castellano que no conocen el quechua y que pertenecen a zonas rurales o urbano marginales de la sierra (y de la costa) del país, hacen uso también de estas formas "híbridas" que reproducen aspectos gramaticales tanto del quechua como del español» (83).

Este hecho coincide con el caso que aquí concierne. No es difícil advertir que el castellano de los niños monolingües de la zona rural de Acolla refleja ser un sistema con rasgos gramaticales que tiene de quechua y castellano pese a que el primero ya no está presente en la intercomunicación de aquellos. Los datos recogidos al respecto dan cuenta de la preponderancia de la variedad andina de castellano en la comunidad de Acolla.

Como afirma Zavala, es posible que la variedad se encuentre por el momento en un proceso de lograr su estabilidad como sistema gramatical y «ya no solo a nivel de interferencia sino, por el contrario, de manera más amplia, a nivel social y dialectal» (84). En el siguiente apartado realizaremos 
una breve reseña de la variedad de castellano en cuestión, que para este trabajo hemos creído por conveniente otorgarle una nominación propia: castellano andino de Acolla.

\subsection{Castellano andino de Acolla}

Acolla es un distrito que se sitúa en la provincia de Jauja y esta a su vez en la región Junín. En esta región se habla el quechua huanca que pertenece al supralecto lingüístico Huaihuash o Quechua I, según A. Torero, o Quechua B, según G. Parker. Este dialecto difiere del quechua sureño hasta el punto de decirse que la comunicación es ininteligible entre ambos dialectos. El quechua huanca está comprendido por tres dialectos: (a) Waylla Wanca hablado en las provincias de Huancayo y Chupaca; (b) Waycha Wanca, en la provincia de Concepción y (c) Shausha Wanca, en la provincia de Jauja (Wroughton 2008: 9).

Wroughton cita a Cerrón-Palomino para asentar que el dialecto quechua Shausha huanca es diferente a las variantes que lo rodean:

como lo señalaba ya don Andrés de Vega (1582) en su 'Descripción' de la provincia de Jauja, al informar que 'cada repartimiento de los tres deste Valle -es decir, Hatun Xauxa (Jauja), Lulin Huanca (Concepción) y Hanan Huanca (Huancayo), R.C-P.- tiene su lenguaje diferente uno de otro, aunque todos se entienden y hablan la lengua general del de los Quichuas'. (2008: 9) 
El lingüista sostiene que existen pocos estudios en relación a la variedad quechua shausha huanca y manifiesta que «el franciscano José Francisco María Ráez, quien vivió en el Valle de Mantaro en el año 1917, reconoció la importancia de este dialecto que conservaba proto-fonemas que habían sufrido cambio en los demás dialectos huancas (Cf. previa referencia 1)» (ídem). La clasificación de la variedad quechua en cuestión como uno de los tres dialectos del valle del Mantaro es reciente, pues data de 1972. En su libro La gramática y el diccionario del Quechua Junín-Huanca (1976), Cerrón-Palomino estudia los tres dialectos quechua de la región como un supralecto y solo hace referencia específica del shausha huanca cuando sus formas gramaticales y léxicas difieren de los demás. Wroughton por su parte, entre enero de 1986 y mayo de 1987, recopila datos de la variedad quechua jaujina de personas que durante su niñez utilizaban el idioma. Las grabaciones y transcripciones que corresponden a cuentos, biografías y descripciones así como a expresiones captadas de una conversación, muestran variaciones aun dentro del dialecto mismo.

En la zona del supralecto huanca, es decir, el Valle de Mantaro, las diferencias étnicas y lingüísticas entre los pueblos de Jauja y los de Concepción y Huancayo son fáciles de percibir según refiere Wroughton:

El QSh se habla en los alrededores de la ciudad de Jauja en el departamento de Junín. Hacia el noreste, la cordillera oriental separa la región de Jauja y la de Tarma y sirve también como línea divisoria entre el QSh y la variedad hablada en la provincia de Tarma. Hacia el este y al otro lado de la cordillera oriental hay varios pueblos de habla shausha. Hacia el norte y noroeste y antes de llegar a La Oroya, se encuentra otra línea divisoria entre el QSh 
y el quechua que se habla a lo largo de las pampas de Junín. La cordillera occidental sirve como frontera entre las comunidades de Jauja y las del departamento de Lima. (Ibidem:11)

El estudioso del quechua shausha huanca advierte además, que se evidencia un cambio hacia una cultura hispano-andina. Además, esta influencia es más notable en la zona de Jauja que en las otras. Y con respecto a la situación sociolingüística de la zona, también es notoria la hispanización, pues «...los padres de familia simplemente no emplean el quechua como primer medio de comunicación. Los niños, por lo tanto, no dominan el idioma» (Ídem); aunque se dice que las mujeres mayores de 50 años hablan quechua y castellano con la misma frecuencia y las mujeres ancianas demuestran su preferencia por el quechua pero se encuentran en las zonas más alejadas.

Esta clara castellanización de los pobladores de la provincia de Jauja, también es perceptible en el distrito de Acolla. Dicha situación se debe a que la región ha estado en contacto permanente con hispanohablantes desde que se inició la conquista. No olvidemos que Jauja fue instaurada por Francisco Pizarro como la primera capital del virreinato. Wroughton resalta, además, algunos factores que han impulsado la castellanización en perjuicio del quechua de la zona de estudio que consideramos no deben ser obviadas en este trabajo (12):

1) Siglos de contacto con los españoles desde el tiempo de la conquista.

2) Un programa educativo con énfasis en la castellanización. 
3) El bajo status que se da al QSh al compararlo con el quechua cuzqueño o ayacuchano.

4) La migración de la población para trabajar en las minas.

5) Los medios de transporte que comunican a la región con Lima, la selva, y los departamentos del sur.

En cuanto a Acolla, es un distrito que cuenta con una población de 8021 habitantes en una extensión territorial de aproximadamente 122.40 $\mathrm{km}^{2}$ (Plan de Desarrollo Concertado del Distrito de Acolla 2011-2021). El distrito, considerado "cuna de músicos», ${ }^{3}$ es dueño de una tradición que se remonta a la época preinca con grupos humanos que se asentaron en el valle de Yanamarca entre el año 10000 a 15,000 A.C., y con una economía que se caracterizaba por actividades de caza, pesca y recolección pasando luego al sedentarismo entre los años 4000 hasta el 2000 A.C. Los grupos étnicos de los Wancas debían afrontar la invasión de los Incas en 1460. Era la época de plena expansión de la cultura inca. La capital del reino Wanca se destruye y se instala la nueva capital en Hatun Xauxa, hoy conocida como Jauja.

Líneas arriba, se dijo que en el distrito de Acolla, el quechua ya no se habla como en los inicios de la colonia. La población en general utiliza el castellano como medio de comunicación (Plan de Desarrollo). En el recorrido por la zona, se observó que generalmente son los ancianos (quienes representan un porcentaje minoritario de la población acollina) los que utilizan el quechua para comunicarse entre sus contemporáneos. Pero, cuando se dirigen a sus hijos adultos y nietos lo hacen en castellano.

3 Frase muy popular para referirse al distrito por albergar al Instituto Superior de Música con rango universitario por Ley N. 23733 
El detrimento en el uso del quechua se debe más a cuestiones sociales y políticas. Cerrón-Palomino declara con respecto a ciertas manifestaciones lingüísticas, refiriéndose específicamente al motoseo, que pese a que son fenómenos naturales de todo proceso de aprendizaje de una segunda lengua, provocan reacciones positivas o negativas. «[...] Tales manifestaciones lingüísticas adquieren un carácter de estigma social y son esgrimidas ideológicamente como un instrumento sutil de opresión y discriminación» (2003: 84).

Dicha discriminación muchas veces se ve reflejada en la intolerancia del hablante de español no-andino hacia el bilingüe o monolingüe de castellano andino. Esta situación genera en los abuelos y padres una necesidad de evitar que sus descendientes aprendan o utilicen el idioma quechua. Domínguez (1990) y Julca (2000) resaltaron esta misma situación en los habitantes de los pueblos de Huánuco y Ancash respectivamente, zonas en las que el quechua era la lengua de comunicación de los ancestros.

El asfaltado casi reciente de la carretera que conecta Jauja y Tarma ha favorecido el movimiento de los pobladores y estudiantes de Acolla hacia Jauja y otras ciudades como Huancayo, Tingo María y Lima. La emigración se ha dado en porcentajes cada vez más elevados, siendo que «el $18.30 \%$ de la población emigra de manera temporal y un $9.30 \%$ emigra de manera definitiva, las causas son diversas como familiares, estudios, trabajo y violencia familiar» (Plan de Desarrollo: 23). Por otro lado, en el distrito de Acolla se viene implementado el servicio eléctrico, situación que ha favorecido la instalación y el acceso a los medios de comunicación masiva como radio, televisión, cable, teléfono e internet, especialmente en la capital del distrito. Aunque no se conoce la proporción de familias que gozan de esta tecnología, muchos de los pobladores, y en especial, jóvenes, 
adolescentes y niños gozan de una mayor exposición al castellano estándar a través de ella y este hecho se convierte en un factor más que favorece la castellanización en perjuicio del quechua shausha huanca de Acolla. Esta castellanización no puede ser caracterizada como estándar o de la norma culta y más bien se distingue por ser un dialecto castellano con un sistema gramatical propio que le hemos atribuido el nombre de castellano andino de Acolla. En un trabajo posterior, es nuestro próximo objetivo presentar un estudio exhaustivo sobre la situación lingüística actual del dialecto de castellano andino de los habitantes del distrito acollino (ver Apéndice 4).

\section{CONCLUSIONES}

- El quechua, idioma oficial del incanato, no se distinguió por ser una lengua uniforme y unificadora. Por el contrario, su diversidad era más resaltante a la llegada de los españoles, quienes en su afán expansionista y evangelizadora, tuvieron que lidiar con las variedades dialectales quechuas en un inicio; llegando a abdicar tal reto para luego impulsar la castellanización de la colonia, especialmente por el lado de los andes peruanos.

- La formación del castellano andino del Perú obedece a múltiple factores que no solo corresponden al contacto de lenguas, sino también a factores de índole geográfico, histórico, social y cultural. Su expansión se ha visto influenciada por la diversidad dialectal quechua de modo que tampoco se puede hablar de un castellano andino único.

- El castellano andino de Acolla igualmente responde a un proceso histórico bastante amplio y nutrido que data de tiempos ancestrales. Actualmente, es una variedad que se configura como un sistema 
lingüístico diferente a los otros por la influencia del dialecto quechua shausha wanca, que, a su turno, difiere de aquellos como el waylla wanca de Huancayo y Chupaca, el waycha wanca de Concepción. Todos ellos pertenecen al supralecto lingüístico Huaihuash de la región Junín. 


\section{REFERENCIAS}

AdELAar, Willer F.H.

2004 The Languages of the Andes. New York: Cambridge University Press.

Aguirre Villanueva, Mauricio

2006 «Panorama lingüístico del Perú a la llegada de los españoles: las lenguas andinas». En Córdova Gastiaburu, Paula (ed.) ¿Cambio o muerte de las lenguas? Reflexiones sobre la diversidad lingüística, social y cultural del Perú. Lima: Universidad Peruana de Ciencias Aplicadas (UPC), pp. 83-109.

Arboleda Toro, Rubén

S/F El español andino: Forma y Función 13 En: Portal de lenguas de Colombia. Diversidad y contacto., Departamento de Lingüística. Universidad Nacional de Colombia, 2000, pp. 85-100. Reseña de Liz Castro en http://www.lenguasdecolombia.gov.co/content/ el-espa\%C3\%B1ol-andino-0, revisado el 28/03/13 a las 10:27 p.m. 
Cerrón-Palomino, Rodolfo

1987 Lingüistica Quechua. Cuzco: Centros de Estudios Rulares Andinos «Bartolomé de las Casas».

2001 «El español en contacto con otras lenguas: la temprana andinización del castellano: Testimonio de Dávalos y Figueroa (1602)». En Cervantes.es. Congresos internacionales de la lengua española. <http://congresosdelalengua.es/valladolid/ponencias/ unidad_diversidad_del_espanol/4_el_espanol_en_contacto/ cerron_r.htm>. Consulta hecha en 27/12/12.

2003 Castellano Andino, Aspectos sociolingüisticos, pedagógicos y gramaticales. Lima: Fondo Editorial de la Pontificia Universidad Católica del Perú.

Constitución Política del Perú

1993

En Justia Perú. <http://peru.justia.com/federales/constitucionpolitica-del-peru-de-1993/>.Consulta hecha en 17/02/13.

Dominguez Condezo, Víctor

1990

Problemas de interferencia Quechua-Español: Estudio Sociolingüistico en el Huallaga Andino. Huánuco: Investigaciones en Ciencias de la Educación (ICE), de la Facultad de Educación UNHEVAL. 
Enguita Utrilla, José M.

2002 «Reseña de Estudios de lingüística andina de German de Granda». Nueva Revista de Filología Hispánica. Vol. LII, N.2, julio-diciembre, El Colegio de México, Distrito Federal, México, pp. 523-533.

Escobar, Ana María

1990 Los Bilingües y el Castellano en el Perú. Lima: Instituto de Estudios Peruanos.

\section{Estrada Ugarte, Christian y Luis Naters Lanegra}

2006

«Diversidad de lenguas y políticas lingüísticas en la historia del Perú». En Córdova Gastiaburu, Paula (ed.) ¿Cambio o muerte de las lenguas? Reflexiones sobre la diversidad lingüística, social y cultural del Perú. Lima: Universidad Peruana de Ciencias Aplicadas (UPC), pp. 161-184.

García Mouton, Pilar

2001 «La división dialectal del español de América: reflexiones y propuesta de trabajo». En Cervantes.es. Congresos internacionales de la lengua española. <http://congresosdelalengua.es/valladolid/ ponencias/unidad_diversidad_del_espanol/2_el_espanol_de_ america/garcia_p.htm>. Consulta hecha en 30/03/13. 
Hardman, Martha J. y Aurora Acosta

2004 ¿De dónde vino el Jaqaru?. En George A Smathers Libraries, University of Florida Digital Collection. <http://ufdc.ufl.edu/ UF00095867/00004/5j>. Consulta hecha en 13/02/13.

Julca Guerrero, Félix Claudio

2000 Uso de las lenguas quechua y castellano en la escuela urbana: un estudio de caso. Tesis para obtener el título de magíster en Educación Intercultural Bilingüe con mención en Formación Docente. Facultad de Humanidades y Ciencias de la Educación, Departamento de Post Grado de la Universidad Mayor de San Simón. Cochabamba, Bolivia.

Merma Molina, Gladys

2004 Lenguas en Contacto: Peculiaridades del español andino peruano. Tres casos de interferencia morfosintáctica. Universidad de Alicante, ELUA, 18, págs. 191-211. En <http://rua.ua.es/ dspace/bitstream/10045/6137/1/ELUA_18_10.pdf>. Revisado el 29/03/13 a las 09:34 p.m.

2007 Contacto lingüistico entre el español y el quechua: un enfoque cognitivo-pragmático de las transferencias morfosintácticas en el español andino peruano. Tesis para obtener el título de doctor. Facultad de Filosofía y Letras del Departamento de Filología Española de la Universidad de Alicante. Alicante, España. En Repositorio Institucional de la Universidad de Alicante.<http://rua. 
ua.es/dspace/bitstream/10045/4114/1/tesis_doctoral_gladys_ merma.pdf>.

NATERS LANEGRA, Luis

2006 «La estructura interna de la lengua y el cambio lingüístico». En Córdova Gastiaburu, Paula (ed.), ¿Cambio o muerte de las lenguas? Reflexiones sobre la diversidad lingüística, social y cultural del Perú. Lima: Universidad Peruana de Ciencias Aplicadas (UPC), pp. 15-40.

PÉREZ SILVA, Jorge Iván

2006 «La Investigación científica del castellano andino: contra la discriminación lingüística». Discurso leído en la Lección Inaugural del Año Académico 2006 de la Facultad de Letras y Ciencias Humanas de la Pontificia Universidad Católica del Perú.

Rataj, Vlastimil

2005 La Influencia del Quechua en el Español Andino. Master's thesis. Faculty of Arts, Department of Philosophy of Masaryk University. Brno, Czech Republic. 
Robledo Ríos, Pilar

2006

"Culturas peruanas: consecuencia del contacto en América». En Córdova Gastiaburu, Paula (ed.) ¿Cambio o muerte de las lenguas? Reflexiones sobre la diversidad lingüística, social y cultural del Perú. Lima: Universidad Peruana de Ciencias Aplicadas (UPC), pp. 161-81.

Tavera PeÑA, María

2006 «Cómo cambian las lenguas y como reaccionamos los hablantes frente a ello». En Córdova Gastiaburu, Paula (ed.) ¿Cambio o muerte de las lenguas? Reflexiones sobre la diversidad lingüistica, socialy cultural del Perú. Lima: Universidad Peruana de Ciencias Aplicadas (UPC), pp. 41-60.

Villegas Paz, Magali Cleofé

2009 Tesis: Estudio morfosintáctico de las oraciones simples transitivas del castellano en el habla de los niños de seis años del CEP José Carlos Mariátegui (Comas). Universidad Nacional Mayor de San Marcos, Lima.

Wroughton, John

2008 Gramática y textos del quechua shausha huanca. Instituto de lingüística de Verano, Documento de trabajo N. 30, Lima: Perú. 


\section{YRMA GARCÍA ROJAS}

Zavala Cisneros, Virginia

1996 «El Castellano de la Sierra del Perú». En Tomoeda, Hiroyasu y Luis Millones, (eds.). La Tradición Andina en Tiempos Modernos. En Osaka, National Museum of Ethnology Repository. <http:// ir.minpaku.ac.jp/dspace/bitstream/10502/1170/1/SER05_000. pdf>. Visita hecha en 22/02/15, pp. 81-131. 


\section{Apéndice 1: Clasificación del Quechua}

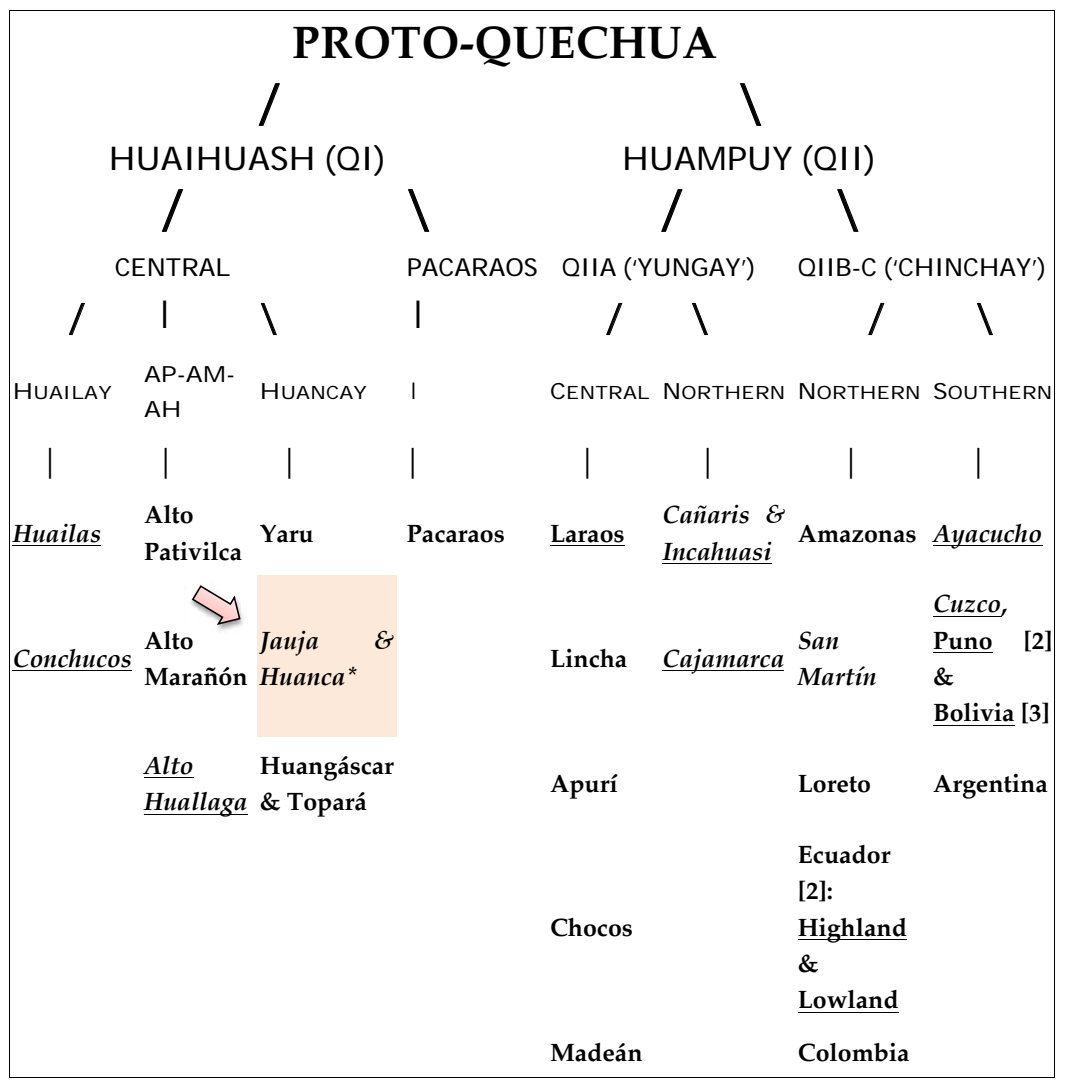

Nota. El encuadre y flecha son nuestros. Tomado de la página web de Heggarty, quien a su vez toma la clasificación de Cerrón-Palomino con ligeras modificaciones <www.quechua.org.uk/Eng/Cpv/Locations.htm> 


\section{Apéndice 2: Mapa de la influencia del quechua}

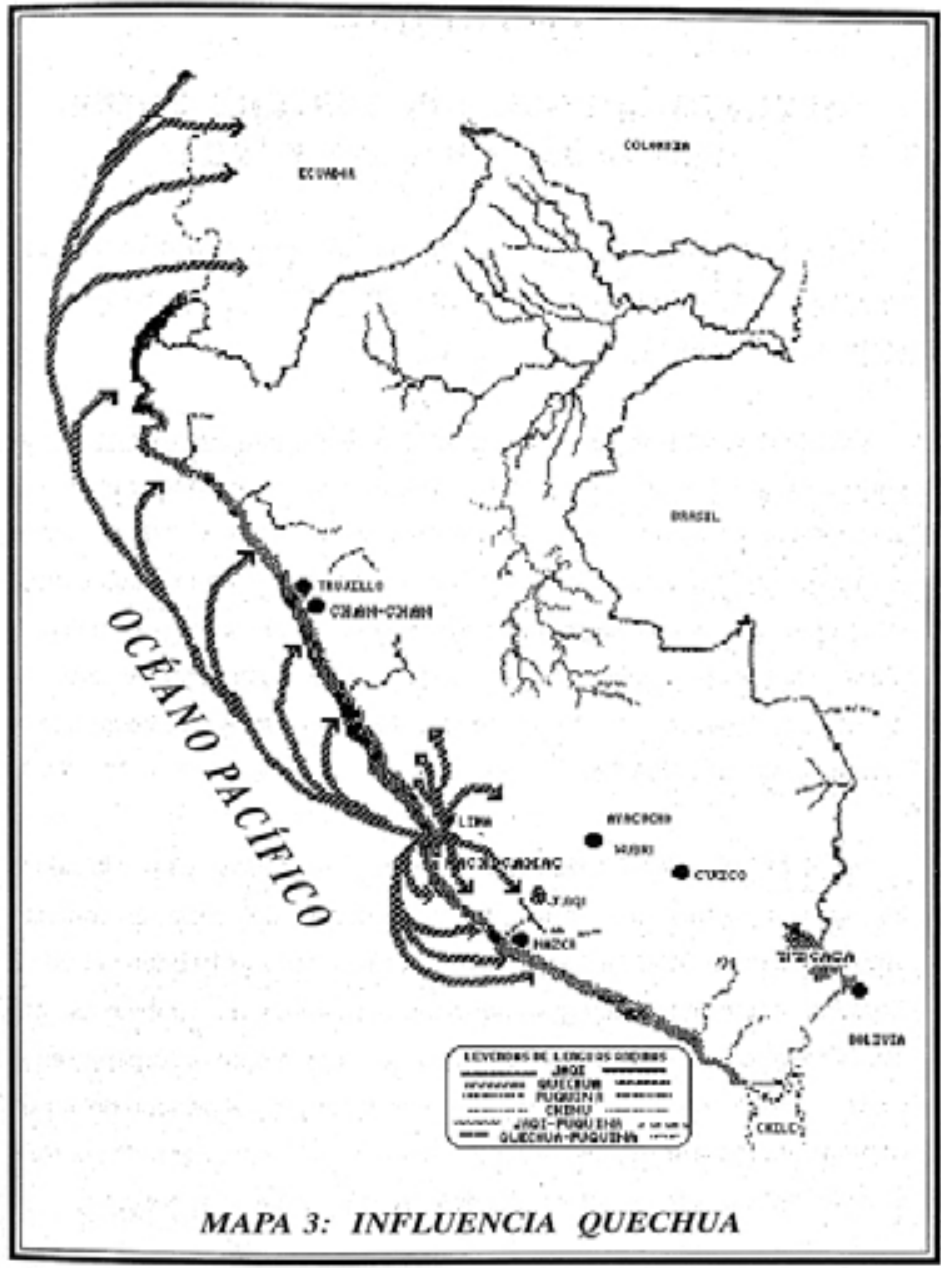

Nota. Tomado de Hardman, Martha J. y Aurora Acosta. ¿¿De dónde vino el Jakaru? Revista Tupinachaka, Tupe, Yauyos, Lima. 2004. 


\section{Apéndice 3. Área del español andino (Andean Spanish Area)}

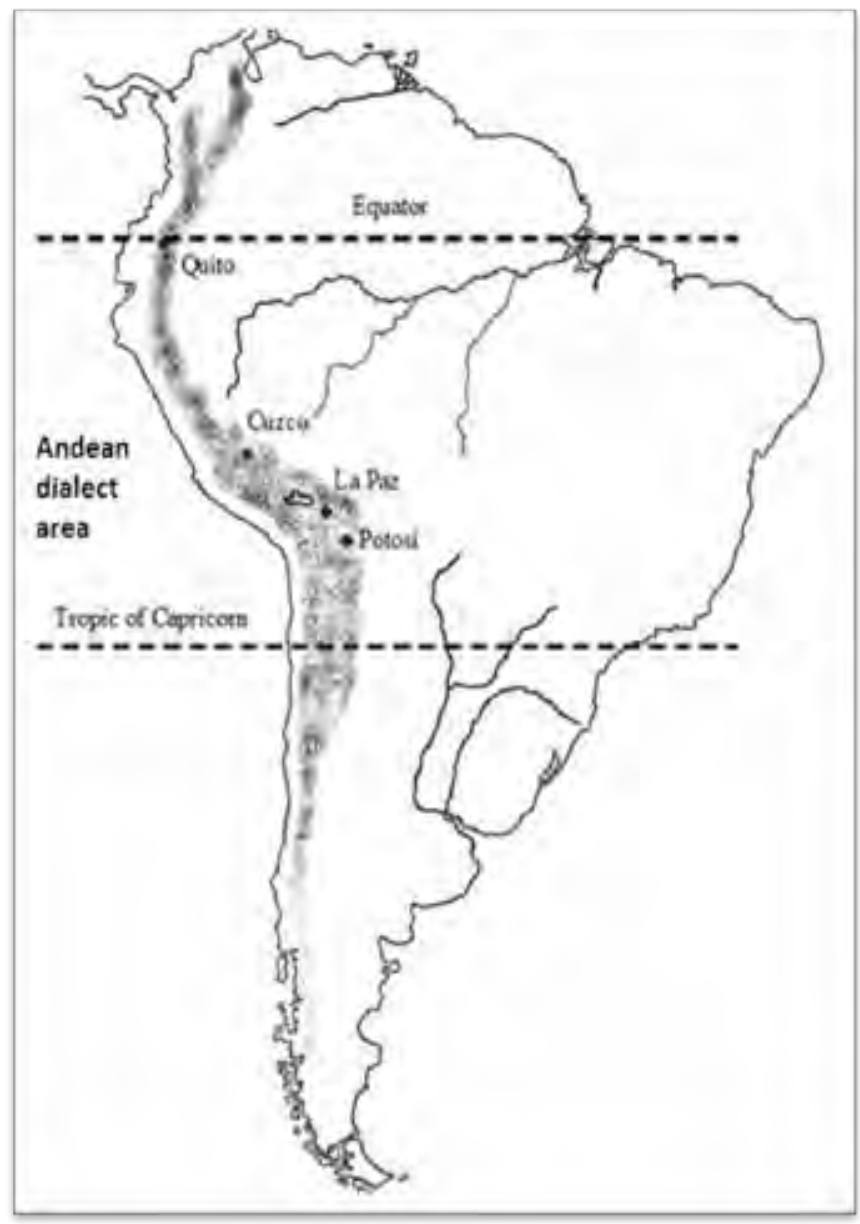

Nota: Tomado de Hardman de Bautista, Martha. «The mutual influence of Spanish and the Andean Languages», Word 33, 1982, pp.143-57. En <www.staff.ncl. ac.uk/i.e.mackenzie/andean.htm> 


\section{Apéndice 4: Zona geográfica en donde se desarrolla el Castellano Andino de Acolla, Jauja, Junín}

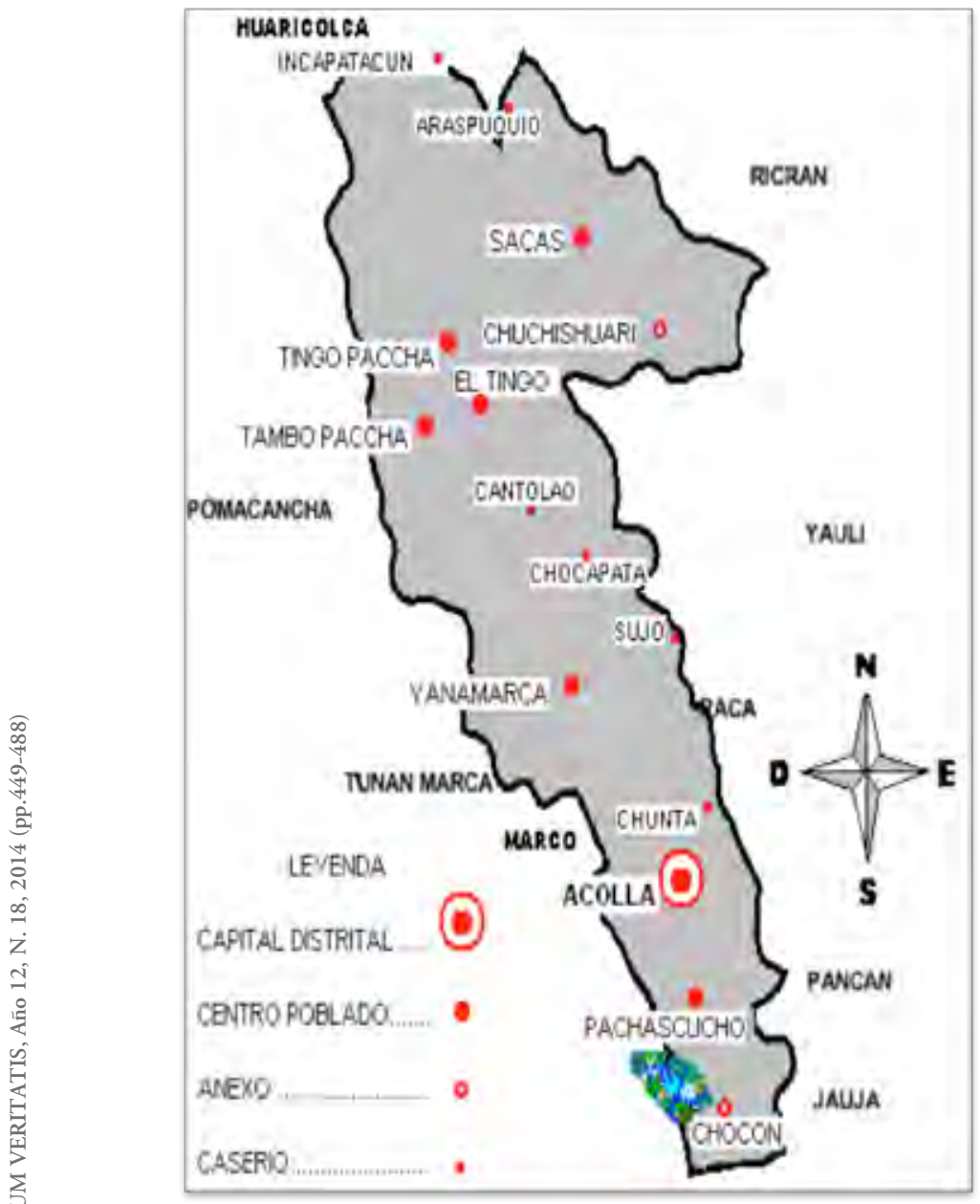

Nota: Tomado de Plan de Desarrollo Concertado del Distrito de Acolla, 2011 2021. 